\title{
Transition from bamboo sap to water: Aquatic habits in the sap beetle Amphicrossus japonicus (Coleoptera: Cucujoidea: Nitidulidae)
}

\author{
Damir KOVAC ${ }^{1}$, Josef JELÍNEK ${ }^{2}$, Rosli HASHIM ${ }^{3}$ and Decha WIWATWITAYA ${ }^{4}$ \\ ${ }^{1}$ Entomologie I, Forschungsinstitut Senckenberg, Senckenberganlage 25, 60325 Frankfurt, Germany; e-mail: \\ damir.kovac@senckenberg.de \\ ${ }^{2}$ Department of Entomology, National Museum, Golčova 1, 14800 Praha 4 - Kunratice, Czech Republic; e-mail: \\ JJ.Nitidula@seznam.cz \\ ${ }^{3}$ Institute of Biological Sciences, Faculty of Science, University of Malaya, 50603 Kuala Lumpur, Malaysia; e-mail: \\ roslihashim@um.edu.my \\ ${ }^{4}$ Faculty of Forestry, Kasetsart University, 50 Paholyothin Rd., Chatuchak, Bangkok 10900, Thailand; e-mail: ffordew@ku.ac.th
}

Key words. Nitidulidae, Amphicrossus, aquatic beetles, Culicidae, bamboo, tree sap, phytotelm, hydrofuge hairs, Oriental Region, Malaysia, Thailand

\begin{abstract}
Amphicrossus japonicus is the first known facultatively aquatic nitidulid. The adult beetles breed in bamboo sap and subsequently enter water-filled bamboo culms. In water they breathe via a ventral air sheath held by hydrofuge pubescence. The beetles are facultative predators and hunt mosquito larvae, which they grab with their forelegs. The trend to facultative predation in Cucujoidea and the transition for beetles in general from semi-liquid decaying organic matter into water is discussed.
\end{abstract}

\section{INTRODUCTION}

Nitidulids (sap beetles) are small to minute terrestrial beetles that feed on tree sap, fungi, fruit juices, carrion, flowers or leaves. A few nitidulids are predaceous and feed on scale insects or have symbiotic relationships with ants or other social Hymenoptera (Kirejtshuk, 1998; Cline, 2005). Some species are pests of field and stored products (Hinton, 1945).

Representatives of the cosmopolitan genus Amphicrossus Erichson, 1843 (Amphicrossinae) inhabit exuding tree sap, which may be an archaic mode of life in Nitidulidae (Kirejtshuk, 2003). The species here investigated, Amphicrossus japonicus Reitter, 1873, is widely distributed in eastern and southeastern Asia, from Japan to Malaysia and the Philippines.

Both larvae and adults of Amphicrossus are saprophagous and known to live in oozing and fermenting sap of trees and bamboos (Hisamatsu, 1973; Hayashi, 1978; Lawrence, 1989). A japonicus was observed in fermenting sap that had exuded from wounds in bamboo culms. In culms with punctured walls rainwater collects inside the hollow interior, creating "bamboo phytotelmata" (Kovac \& Streit, 1996). We have observed adult $A$. japonicus entering the water in these phytotelmata and report on their adaptations for life in this aquatic habitat.

\section{MATERIAL AND METHODS}

Field observations were carried out in 1994 and 2005 in West Malaysia (Ulu Gombak Field Studies Centre near Kuala Lumpur) and Northern Thailand (Mae Hong Son Province, District Pangmapha). Most of our investigations were conducted on freshly cut bamboo stumps (Fig. 1), because beetles could be easily observed using a Zeiss ${ }^{\mathrm{R}}$ prism-headlens F $(8 \times)$. Prey captured by $A$. japonicus were procured with forceps and identified in the laboratory. For SEM examination, beetles were dried in hexamethyldisilazane (Nation, 1983).

Individual beetles were continuously observed for up to $6 \mathrm{~h}$ to determine if they remained submerged for extended periods of time. At a location in West Malaysia the number of submerged beetles were counted once per hour between 8.30 and 21.30 in seven bamboo stumps (Experiment 1). It rained between 17.30 and 10.00. Night began shortly after 19.00. In one bamboo stump temperature and $\mathrm{pH}$ were measured. Beetles observed in a prey-capturing position or feeding on mosquito larvae were recorded separately.

\section{RESULTS}

\section{Habitat}

A. japonicus were found at sap exuding from injured culms of Gigantochloa scortechinii Gamble, 1896, Dendrocalamus giganteus Munro, 1868, Cephalostachyum pergracile Munro, 1868 and other bamboo species. Sap frequently oozes from young, upright bamboo shoots injured by a Cyrtotrachelus Schoenherr, 1838 weevil (Kovac \& Azarae, 1994). Sometimes sap also exuded from the stumps of fully grown, freshly cut bamboo culms (Fig. 1). Beetles were found in water-filled stumps of freshly cut young bamboo shoots and behind culm sheaths of young bamboo shoots.

In stumps of freshly cut older bamboo culms the liquid was mostly clear and originated both from plant sap and rain water. The $\mathrm{pH}$ of the liquid was 3.5 (3.37-3.55 in Experiment 1) and 5.5 in stumps not containing sap. In occupied stumps the water temperature was similar to ambient air temperature. The highest water temperature recorded was $32^{\circ} \mathrm{C}$ for a culm in full sun.

After $\sim 2-5$ days the sap not in contact with water fermented and became more viscous, white and had a fruity smell. $A$. japonicus arrived at bamboo only after fermentation had started. After $\sim 3-4$ weeks this microhabitat lost its attractiveness to Amphicrossus, possibly because of the lack of fermentation products.

The beetles stayed either in the water or fermented bamboo sap oozing down on the external wall of the bamboo stump. The maximum number of $A$. japonicus submerged in a single bamboo stump was 52 . When not in the water the beetles were barely visible, because they remained submerged in sap or were 


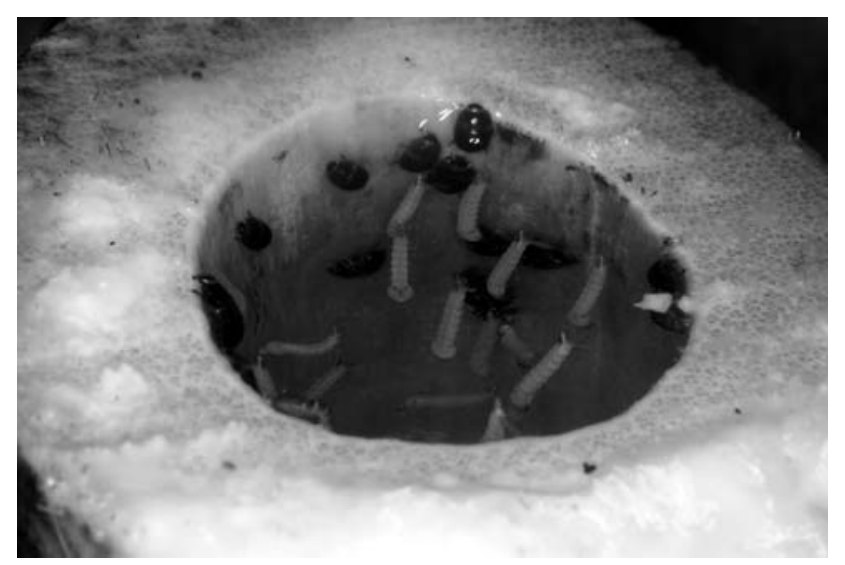

Fig. 1. Amphicrossus japonicus and mosquito larvae in a water-filled bamboo stump. Note the white, fermenting bamboo sap on the cut surface. Internal diameter of bamboo stump $\sim 3.5$ $\mathrm{cm}$.

hidden behind bamboo culm sheaths. Larvae of $A$. japonicus stayed in bamboo sap and did not enter the water.

\section{Aquatic habits}

In water-filled bamboo stumps most adult $A$. japonicus remained at depths of $\sim 1-2 \mathrm{~cm}$. Some individuals, however, did descend to the bottom of the stump $\sim 10 \mathrm{~cm}$ below the water surface. When disturbed, e.g., by disturbing the water, by projecting a shadow or by generating a flash of light, the beetles submerged or fled deeper into the water. In response to prolonged disturbance, like heavy rain in Experiment 1, some left the water, while most remained submerged (17.30: 101 submerged; $18.30: 74 ; 19.30: 96 ; 21.30: 102)$. The beetles usually walked on the inner wall of the stump or leaves that collected inside the stump. They avoided the detritus-covered bottom, which did not provide a surface with which they could cling to. When the beetles were unable to cling to a substrate or when they released their hold, they floated to the surface. Once at the surface the beetles used their legs to swim to the bamboo wall.

The beetles retained a layer of air at their ventral surface when submerged (Fig. 3). This layer of air covered the basal part of the head, pronotum and a narrow region at the anterior

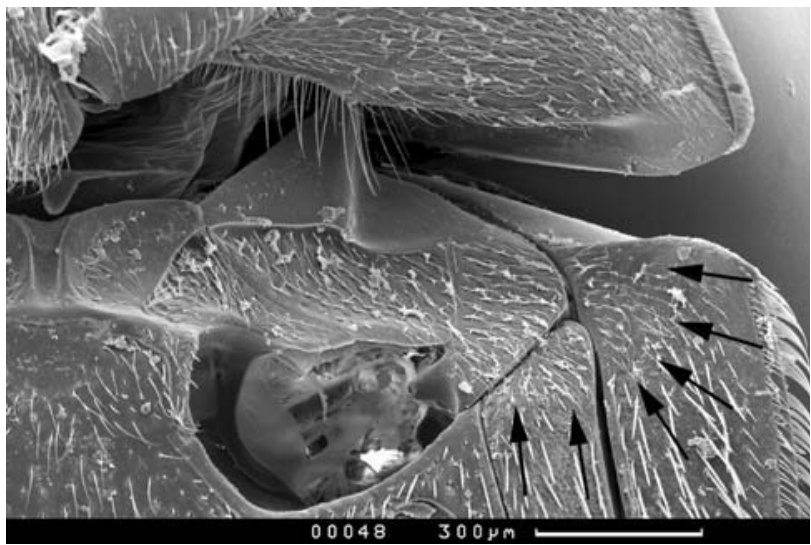

Fig. 2. Details of the ventral surface of the pronotum and mesothorax of $A$. japonicus (SEM-photograph, foreleg removed). Arrows indicate the boundary between small hairs (mainly located on pronotum, above boundary) and large hairs located on mesothorax (below boundary). Only the small hairs retained the air bubble when submerged.

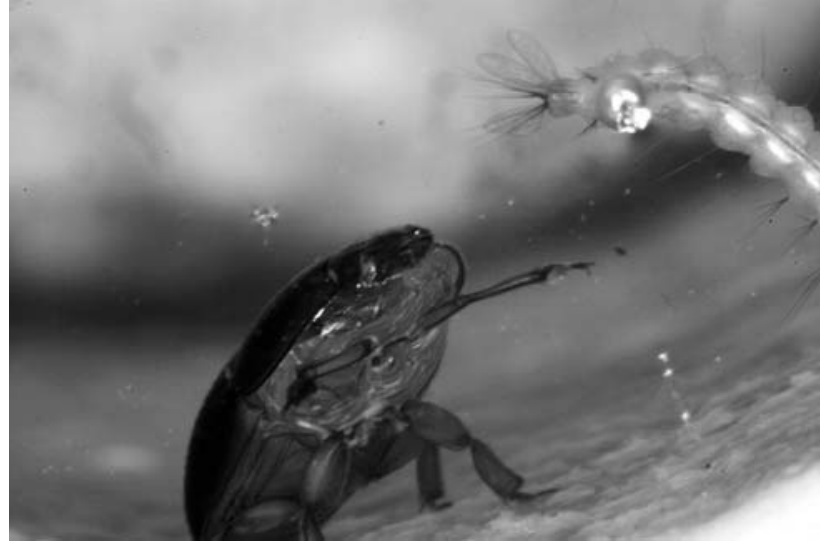

Fig. 3. A submerged A. japonicus in prey-capturing posture. The anterior part of the beetle is raised and fore legs extended sideways. Note the air sheath covering the ventral part of the basal region of head and pronotum. Beetle body length $\sim 5 \mathrm{~mm}$.

edge of the mesothorax. The mouthparts were surrounded by water whereas the antennae lay flat within the air sheath. The mesosternum, metasternum and abdominal sternites, and dorsal body surface did not retain an air sheath. In dorsal view a narrow air sheath was visible between head and pronotum, and between pronotum and base of elytra. SEM-investigation of the body surface showed that those body parts that retained an air sheath were pubescent and had a squamous cuticular surface. The hydrofuge hairs were $\sim 60 \mathrm{~mm}$ long and the density was $3 \times 10^{4}$ per $\mathrm{cm}^{2}$. The rest of the body surface was also pubescent, but the hairs were longer $(\sim 100 \mathrm{~mm})$ and sparser $\left(1 \times 10^{4}\right.$ per $\mathrm{cm}^{2}$ ) and the cuticular surface smooth (Fig. 2).

Individual beetles were observed to remain in the water for up to $6 \mathrm{~h}$. To obtain fresh air the beetles walked upwards, turned their head sideways and touched the water surface. This resulted in an opening in the air sheath between the head, pronotum and foreleg, which probably with the aid of the antenna broke the water's surface film. On the side, the air was taken up, the antenna was permanently raised upwards (Fig. 4). The beetles remained in this position for $\sim 30 \mathrm{~s}(40 ; 15 ; 30 ; 60 ; 30 ; 20 ; 7 ; 30$; $15 \mathrm{~s})$. At a temperature of $22{ }^{\circ} \mathrm{C}$ the beetles surfaced every $2-3$ minutes $(185 ; 200 ; 220 ; 195 ; 210 ; 180 ; 70 ; 65 ; 215 ; 160 \mathrm{~s})$. At higher temperatures the surfacing frequency was higher. In bamboo sap air was replenished at different parts of the air sheath, for example, dorsally between the head and pronotum.

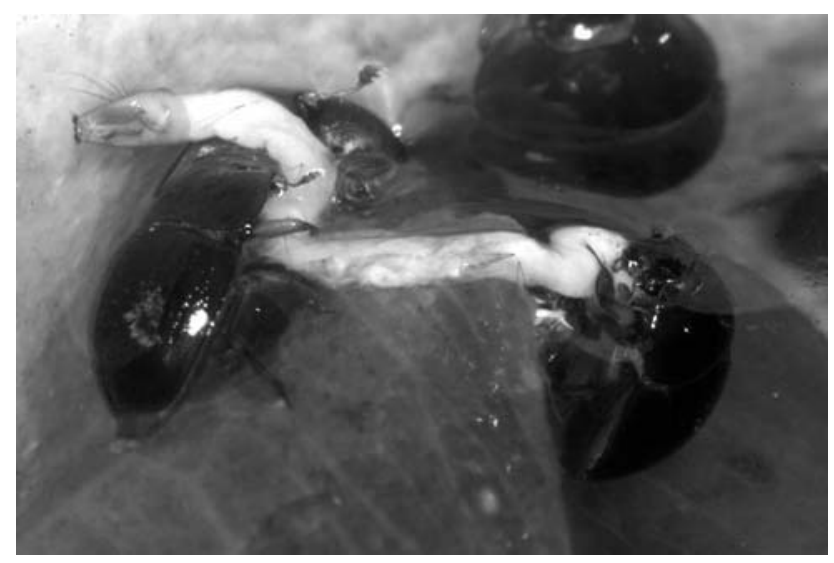

Fig. 4. Two A. japonicus beetles feeding on a mosquito larva. Note the raised beetle antenna on the side of the body protruding from the water. 


\section{Predatory behaviour}

While in water the beetles sometimes assumed a peculiar body posture. The anterior body was raised and forelegs lifted up and extended sideways (Fig. 3), while the beetle was orientated downward or, less frequently, to the side or upward. When a mosquito larva approached the beetles quickly turned and attempted to seize it with their forelegs. They slapped their forelegs together simultaneously and then jerked their anterior body downward. In most cases the mosquito larvae escaped and the beetles resumed their ambush positions. Some beetles continued to hunt for more than an hour without success. In Experiment 1 up to $17 \%$ of the submerged beetles assumed the hunting position at the same time (13.30: 109 beetles submerged, 19 in hunting posture).

When a beetle succeeded in seizing a mosquito it would begin to feed on it under water, but would soon ascend to the surface for air. At the surface the beetles would continue to eat while in the breathing posture (Fig. 4). Small mosquito larvae were consumed entirely, whereas large larvae were eaten only in part and then abandoned. Frequently other beetles joined their eating companions, tearing at a mosquito larva in different directions. In one case, four beetles fed for an hour on a large mosquito larva, leaving only an empty skin, which was perforated by the beetles' mandibles but otherwise intact. These remnants were subsequently consumed by other mosquito larvae, so that only sclerotized body parts like the breathing tube remained.

Sometimes hunting beetles were pushed off the bamboo wall by the violent defensive movements of the mosquito larva, resulting in both insects floating to the water surface. The beetle continued to embrace the mosquito larva or a severed part thereof with its forelegs. The beetle would continue feeding on the prey at the surface while breathing air. SEM images of the forelegs revealed no specific features for capturing mosquito larvae (spines, etc.).

In the field $A$. japonicus mainly fed on mosquito larvae, but also on a variety of other insects when the opportunity arose. In one case an individual caught an aquatic phorid larva, whereas others consumed flies, small wasps or termites that had fallen onto the water surface. Beetles in tree sap attempted to press fly larvae to the ground with their head. In one case a beetle fed on a drosophilid larva, which it held with its forelegs.

\section{DISCUSSION}

Adult $A$. japonicus may remain active in water for many hours. When submerged they use an air sheath, which appears to have several functions. The sheath prevents intrusion of water into the tracheal system, serves as an air reservoir, as a physical gill (at low temperatures) and also enables rapid ascent to the water surface. Deoxygenated air is replenished in a stereotypical manner at the water surface, probably with the aid of the antennae. In some water beetles, e.g. Hydraenidae, the antennae are also used to break the water's surface film so that the air reservoir can be replenished (Perkins, 1997). In summary, $A$. japonicus exhibits the same specializations to aquatic life as found in true aquatic beetles or water bugs (see Thorpe, 1950).

Larvae of Amphicrossus did not enter the water on their own, although they display some characters, which may be regarded as adaptations to aquatic life and feeding on a liquid substrate, such as strongly prolonged spiracular tubes and prosthecal comb-hairs on mandibles (Hayashi, 1978). These characters are shared with other beetles possessing similar feeding habits, e. g. Nosodendridae or other Nitidulidae; i.e. Glischrochilus Reitter, 1873 and Cryptarcha Shuckard, 1839 (Lawrence, 1989).

Structural preadaptations for living in water, like hydrofuge pubescence, certainly were present before the beetles occupied an aquatic habitat and are a precondition for living in liquid tree sap. Other nitidulids occurring on bamboo (e.g. Urophorus Murray, 1864 and Epuraea Erichson, 1843) also have a ventral air sheath when forcibly submerged in water. However, these beetles always remained in the tree sap.

While in water, $A$. japonicus kept moving its mandibles, presumably filtering yeasts, fungi and other microorganisms. In addition, A. japonicus is facultatively predaceous on other insects. The development of a specialized strategy for hunting mosquito larvae suggests that this ample food resource was a selective force for the evolution of A. japonicus in aquatic ecosystems. Other terrestrial beetles, e.g., the staphylinid Hesperus kovaci Schillhammer, 2002 also enter water to hunt mosquito larvae in bamboo phytotelmata (Schillhammer, 2002).

Available evidence suggests that facultative predation in primarily saprophagous species occurs in various Cucujoidea. Thus, Nuorteva (1956) observed that larvae of the European Glischrochilus quadripunctatus (Linnaeus, 1758) (Nitidulidae: Cryptarchinae) eat eggs and larvae of Scolytidae, but may be reared on rotting fruit as well. According to McCoy \& Brindley (1961) the otherwise saprophagous Nearctic Glischrochilus quadrisignatus (Say, 1835) may attack previously injured larvae of the European corn borer [Ostrinia nubilalis (Hübner, 1796), Lepidoptera: Pyralidae] (see also Carlson \& Chiang, 1973). Similarly, both larvae and adults of some saprophagous species of Rhizophagus Herbst, 1793 (Monotomidae: Rhizophaginae) may occasionally feed on the eggs and/or larvae of bark beetles (Curculionidae: Scolytinae), as observed by Beaver (1966) in Rhizophagus bipustulatus (Fabricius, 1792) and Merlin et al. (1986) in R. dispar (Paykull, 1800). In the case of Rhizophagus the versatile feeding habits of some species may have been a preadaptation for the obligate predaceous habits of $R$. grandis Gyllenhal, 1827, which is considered to be an important enemy of the bark beetle Dendroctonus micans (Kugelann, 1794) (Grégoire et al., 1985).

A trend towards facultative predation is also observed in other beetles dwelling in slime fluxes associated with tree wounds or under bark. Costa et al. (1986) reported that Nosodendridae (Bostrichoidea) feed on Diptera larvae. However, the specialized larval mandibles as well as the fungal hyphae and conidia observed in the gut of both larval and adult Nosodendridae suggest, according to Lawrence (1989), that fly larvae are not the main source of food.

The ancestors of Cucujoidea probably lived under the bark of trees, as do some of their present representatives. Such subcortical habitats seem to have played an important role throughout the evolutionary history of Coleoptera. The first beetles, which may have appeared in the Palaeozoicum, are thought to have evolved in subcortical cavities of trees. Kirejtshuk (1991) suggested that at the end of the Palaeozoic and beginning of the Mesozoic these beetles spread to semi-aquatic and aquatic habitats via an intermediate stage of inhabiting wet or submerged trees.

Our observations indicate that beetles living in tree sap and probably in other semi-liquid decaying organic matter may develop structural adaptations predisposing them for living in water. Quite possibly, some of the many aquatic evolutionary beetle lineages, e.g. Hydrophilidae, may have originated in semi-liquid decaying organic matter.

ACKNOWLEDGEMENTS. Thanks are due to the German Research Organization (DFG) for funding part of the field work. 


\section{REFERENCES}

BEAVER R.A. 1966: Notes on the fauna associated with elm bark beetles in Wytham Wood, Berks. 1. Coleoptera. Entomol. Mon. Mag. 102: 163-170.

CARlson R.E. \& Chiang H.C. 1973: Reduction of an Ostrinia nubilalis population by predatory insects attracted by sucrose sprays. Entomophaga 18: 205-211.

CuINE A.R. 2005: Revision of Pocadius Erichson (Coleoptera: Nitidulidae). Dissertation of the Louisiana State University, $376 \mathrm{pp}$.

Costa C., Casari-Chen S.A. \& Teixeira E.P. 1986: Larvae of Neotropical Coleoptera XVI. Nosodendridae. Rev. Bras. Entomol. 30: 291-297.

Grégoire J.-C., Merlin J., Pasteels J.M., Jaffuel R., Vouland G. \& SCHVESTER D. 1985: Biocontrol of Dendroctonus micans by Rhizophagus grandis in the Massif Central (France): a first appraisal of the mass-rearing and release methods. Z. Angew. Entomol. 99: 182-190.

HAYASHI N. 1978: A contribution to the knowledge of the larvae of Nitidulidae occurring in Japan (Coleoptera: Cucujoidea). Insecta Matsum. (N.S.) 14: 1-97.

Hinton H.E. 1945: A Monograph of the Beetles Associated with Stored Products. Vol. 1. Trustees of the British Museum, London, $433 \mathrm{pp}$.

Hisamatsu S. 1973: Biology of Nitidulidae. The Insectarium 10 4-7 [in Japanese].

KIREJTSHUK A.G. 1991: Evolution of mode of life as the basis for division of the beetles into groups of high taxonomic rank. In Zunino M., Bellés X. \& Blas M. (eds): Advances in Coleopterology. Asociación Europea Coleopterologia, Barcelona, Torino, pp. 249-262.

Kirejtshuk A.G. 1998: Nitidulidae (Coleoptera) of the Himalayas and Northern Indochina, Part 1: Subfamily Epuraeinae. Theses Zoologicae, Vol. 28. Koeltz Scientific Books, Koenigstein, $489 \mathrm{pp}$.

KiREJTSHUK A.G. 2003: Subcortical space as an environment for palaeoendemic and young groups of beetles, using mostly examples from sap-beetles (Nitidulidae, Coleoptera). In Bowen P.C. (ed.): Proceedings of the Second Pan-European
Conference on Saproxylic Beetles. People's Trust for Endangered Species, London, pp. 50-56.

Kovac D. \& Azarae I. 1994: Depredations of a bamboo shoot weevil: an investigation. Nature Malays. 19(4): 115-122.

Kovac D. \& Streit B. 1996: The arthropod community in bamboo internodes in Peninsular Malaysia: microzonation and trophic structure. In Edwards D.S., Booth E.E. \& Choy S.C. (eds): Tropical Rainforest Research - Current Issues. Monographiae Biologicae 74. Kluwer Academic Publishers, Dordrecht, Boston, London, pp. 85-99.

LaWRENCE J.F. 1989: Mycophagy in the Coleoptera: feeding strategies and morphological adaptations. In Wilding N., Collins N.M., Hammond P.M. \& Webber J.F. (eds): InsectFungus Interactions. Academic Press, London, pp. 1-23.

McCoY C.E. \& BRINDLEY T.A. 1961: Biology of the four-spotted fungus beetle, Glischrochilus q. quadrisignatus and its effect on European corn borer populations. J. Econ. Entomol. 54: 713-717.

Merlin J., Parmentier C. \& Gregoire J.C. 1986: The feeding habits of Rhizophagus dispar (Col., Rhizophagidae), an associate of bark beetles. Med. Fac. Landbouww. Rijksuniv. Gent 51: 915-923.

NATION J.L. 1983: A new method using hexamethyldisilazane for preparation of soft insect tissues for scanning electron microscopy. Stain Technol. 58: 347-351.

Nuorteva M. 1956: Über den Fichtenstamm-Bastkäfer Hylurgops palliatus Gyll., und seine Insektenfeinde. Acta Entomol. Fenn. 13: 1-118.

Perkins P.D. 1997: Life on the effective bubble: exocrine secretion delivery system (ESDS) and the evolution and classification of beetles in the family Hydraenidae (Insecta: Coleoptera). Ann. Carnegie Mus. 66: 89-207.

SChillhammer H. 2002: Three new Oriental species of Hesperus Fauvel (Coleoptera: Staphylinidae). Koleopt. Rdsch. 72: 127-135.

THORPe W.H. 1950: Plastron respiration in aquatic insects. Biol. Rev. Cambridge Phil. Soc. 25: 344-390.

Received May 29, 2006; revised and accepted April 23, 2007 